\title{
Mitigating Traffic Congestion on I-10 Mississippi River Bridge in Baton Rouge, LA
}

\author{
Samir Ahmed ${ }^{1, *}$, Osama Osman ${ }^{2}$, and Julius Codjoe ${ }^{3}$ \\ ${ }^{1}$ School of Civil \& Environmental Engineering, Oklahoma State University, Stillwater, OK 74075 \\ ${ }^{2}$ Virginia Tech Transportation Institute, Blacksburg, VA 24060 \\ ${ }^{3}$ Louisiana Transportation Research Center, Baton Rouge, LA 70808
}

\begin{abstract}
The purpose of this study was to identify and evaluate treatments and strategies to mitigate traffic congestion on the I-10 Mississippi River Bridge in Baton Rouge, LA. Based on VISSIM simulation results, combination of supply- and demand-oriented measures will be required. Rehabilitation of the old bridge on US-190 and the existing US-190/US-61 corridor, overall demand management of I-10 EB traffic, reduction in percent trucks traveling eastbound on I-10 during the A.M. peak, and ramp metering at the onramp west of the I-10 Mississippi River Bridge appear to be feasible and effective solutions.
\end{abstract}

\section{Introduction}

I-10 is the most heavily traveled coast-to-coast interstate in the U.S. It is also a national freight corridor of significant importance to the economy. The portion of I10 through Baton Rouge, LA was constructed in the 1960's as a four-lane freeway (two lanes per direction). Traffic demand in Baton Rouge has been growing steadily and currently exceeds the capacity of the corridor during the morning and afternoon peak periods. Severe traffic congestion is a recurring problem particularly along the segment of I-10 from Louisiana Highway 415 (LA 415) across the Mississippi River Bridge (MRB) to the I-10/I-12 merge. Capacity improvements to $\mathrm{I}-10$ and $\mathrm{I}-12$ in the eastern suburbs helped deliver more traffic to the core of the urban area, thus compounding the traffic congestion on I-10 and the MRB. Figure 1 illustrates the existing I-10 traffic issues in Baton Rouge.

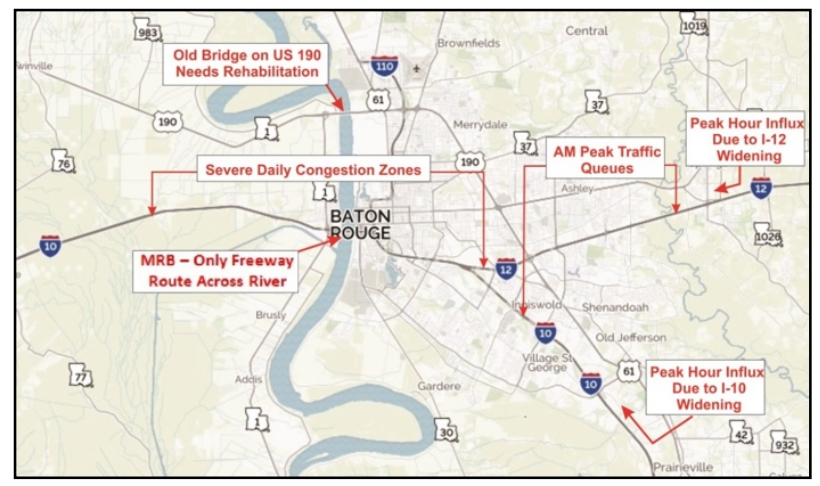

Fig. 1. Existing I-10 traffic issues in Baton Rouge, LA.
The I-10 MRB is the only freeway link connecting east and west Baton Rouge areas. An older bridge on the US-190/US-61 corridor is located 4.5 miles upstream of the I-10 MRB. Travelers choose to use the I-10 MRB because of ease of access to several significant locations in Baton Rouge and the poor condition of the roadway network leading to the old bridge. Relieving congestion on the I-10 MRB is challenging especially that capacity expansion is an expensive solution. For instance, a new bridge could significantly reduce congestion; however, it will cost around $\$ 1$ billion [1]. Therefore, other solutions such as Active Traffic Management (ATM), Intelligent Transportation Systems (ITS), and the application of Travel Demand Management (TDM) techniques must be investigated. As such, this study focused on evaluating several supply-oriented and demand-oriented solutions to mitigate the congestion problem at the I-10 MRB site.

\section{Previous studies}

Several studies have been conducted in the past 20 years to address traffic congestion on I-10 in Baton Rouge by adding capacity and eliminating bottlenecks. These studies can be grouped into two broad groups: 1) I-10 corridor projects, and 2) off-corridor projects. Examples of the I-10 corridor studies include the I-10 Baton Rouge Major Investment Study [2], the I-10 Corridor Improvements Stage-0 Feasibility Study [3], and the Baton Rouge Loop [4]. Proposed capacity improvements included widening of I-10 by adding a third lane in each direction and making major geometric improvements to merge, diverge, and weaving segments along the 3.5mile corridor between the Interstate 10/12 split interchange and the I-10 MRB [5].

\footnotetext{
* Corresponding author: sahmed@okstate.edu
} 
A notable example of the off-corridor projects that have been proposed is the Baton Rouge Urban Renewal and Mobility Plan (BUMP) envisioned by AECOM [6]. The BUMP project can effectively reduce the demand on the I-10 corridor through the core urban area and across the I-10 MRB. Figure 2 illustrates the proposed alignment of the BUMP project. Under the AECOM proposal, the existing US-190/US-61 corridor is utilized to construct a $60-70 \mathrm{mph}$ toll-road connecting I-10 in West Baton Rouge Parish with I-12 and I-10 in East Baton Rouge Parish. Traffic demand will be shifted from the existing heavily congested I-10 MRB to the underutilized old US-190 Bridge just 4.5 miles upstream. Access to existing business and other land- uses along the US-190/US-61 corridor will be maintained through a toll-free system of frontage roads using existing right of way. In addition to improving regional mobility, the BUMP project was planned to provide an urban renewal stimulus for the older part of the US- 61/US-190 corridor north of Florida Boulevard in East Baton Rouge Parish.

The supply-oriented proposals discussed earlier (both I-10 corridor projects and off-corridor projects) have not been realized for various reasons including lack of political and/or community support, lack of funding, right of way issues, and environmental impacts. While the stakeholders and leadership in Baton Rouge keep pondering these potential supply-oriented improvements, traffic demand keeps increasing and traffic congestion keeps getting worse.

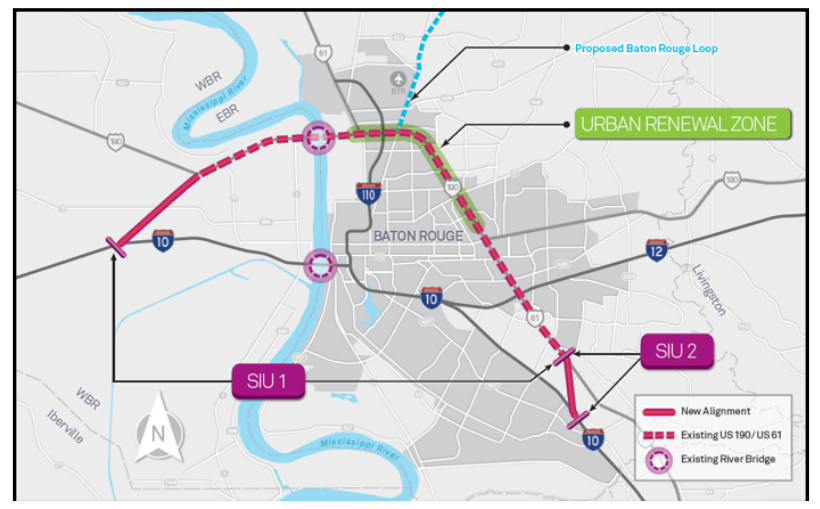

Fig. 2. AECOM Baton Rouge urban renewal and mobility plan (BUMP).

\section{Research methodology}

The research methodology involved: 1) identification of potential data sources to model the I-10 MRB using microsimulation, 2) calibration, and validation of the simulation platform required for the study, 3) development of treatments and strategies for testing using the simulation platform, and 4) evaluating the effectiveness of proposed solutions. Following is a discussion of the different steps of the research methodology.

\subsection{Identification of data sources}

The research team identified four main sources of data: the Louisiana Department of Transportation and
Development (LADOTD), the Streetlytics database developed by CitiLabs, the National Performance Management Research Data Set (NPMRDS) maintained by FHWA, and traffic signal timing data (TSTD) from the City of Baton Rouge and LADOTD. A partial VISSIM simulation model acquired from the LADOTD along with the encoded hourly volumes served as the primary data source. Data obtained from the other sources (Streetlytics, NPMDRS, and TSTD) were used for model calibration and validation. Table 1 summarizes the data available in this study.

\subsection{Simulation model calibration and validation}

The objective of this step was to have a working model that matches the real-world traffic conditions to the extent possible. After several runs and investigation of all intersections and roadway segments in the model, it was clear that in addition to the regular calibration process which includes adjustment of car following and lane change parameters, routing decisions were another important parameter that needed to be tackled. This was based on comparison of travel time data produced by the model with those obtained from Streetlytics and NPMRDS.

Table 1. Traffic data available.

\begin{tabular}{|c|c|c|c|c|}
\hline Source & Date Type & \begin{tabular}{|c|} 
Data \\
Resolution
\end{tabular} & Duration & Remarks \\
\hline LaDOTD & $\begin{array}{c}\text { Traffic } \\
\text { Volume }\end{array}$ & $\begin{array}{l}\text { Hourly } \\
\text { Volumes }\end{array}$ & $\begin{array}{c}3 \text { Hours } \\
\text { A.M. Peak } \\
4 \text { Hours } \\
\text { P.M. Peak }\end{array}$ & $\begin{array}{c}\text { Demand } \\
\text { Input in } \\
\text { VISSIM } \\
\text { Microscopic } \\
\text { Simulation } \\
\text { Model } \\
\end{array}$ \\
\hline $\begin{array}{l}\text { Streetlytics } \\
\text { (Citilabs) }\end{array}$ & $\begin{array}{l}\text { Traffic } \\
\text { Volume }\end{array}$ & $\begin{array}{c}\text { 3-Hour } \\
\text { A.M \& 3- } \\
\text { Hour P.M. } \\
\text { Aggregated } \\
\text { Volume }\end{array}$ & $\begin{array}{l}3 \text { Hours } \\
\text { A.M. Peak } \\
4 \text { Hours } \\
\text { P.M. Peak }\end{array}$ & $\begin{array}{c}\text { Calibration } \\
\& \\
\text { Validation } \\
\text { of VISSIM } \\
\text { Microscopic } \\
\text { Simulation } \\
\text { Model } \\
\end{array}$ \\
\hline $\begin{array}{c}\text { National } \\
\text { Performance } \\
\text { Management } \\
\text { Research } \\
\text { Data Set } \\
\text { (NPMRDS) }\end{array}$ & $\begin{array}{c}\text { Travel } \\
\text { Time \& } \\
\text { Speed }\end{array}$ & $\begin{array}{l}\text { Hourly } \\
\text { Average }\end{array}$ & $\begin{array}{c}\text { Several } \\
\text { hours in } \\
\text { both A.M. } \\
\text { and P.M. } \\
\text { peak } \\
\text { periods }\end{array}$ & $\begin{array}{c}\text { Calibration } \\
\& \\
\text { Validation } \\
\text { of VISSIM } \\
\text { Microscopic } \\
\text { Simulation } \\
\text { Model }\end{array}$ \\
\hline $\begin{array}{l}\text { City of } \\
\text { Baton } \\
\text { Rouge \& } \\
\text { LADOTD }\end{array}$ & $\begin{array}{c}\text { Traffic } \\
\text { Signal } \\
\text { Timing } \\
\text { (TST) }\end{array}$ & $\begin{array}{c}\text { Cycle } \\
\text { length, } \\
\text { split, offsets }\end{array}$ & $\begin{array}{c}\text { Several } \\
\text { hours in } \\
\text { both A.M. } \\
\text { and P.M. } \\
\text { peak } \\
\text { periods }\end{array}$ & $\begin{array}{c}\text { Calibration } \\
\& \\
\text { Validation } \\
\text { of VISSIM } \\
\text { Microscopic } \\
\text { Simulation } \\
\text { Model }\end{array}$ \\
\hline
\end{tabular}

Note: The Capital Region Planning Commission (CRPC) is currently collecting traffic data in the study area. These data were not available during the course of the study.

\subsection{Proposed solutions}

Several solutions for mitigating traffic congestion on the I-10 MRB were identified and tested using the VISSIM 
simulation model. These solutions can be classified as supply-oriented or demand-oriented solutions. Table 2 presents summary of the key strategies and treatments included in the simulation scenarios. A total of 10 simulation runs were performed for every proposed solution.

\subsection{Evaluating the effectiveness of proposed solutions}

For every solution, several measures of effectiveness (MOEs) and metrics were determined from the simulation results. The MOEs included delay, throughput, speed, vehicle-miles traveled (VMT), delay cost, and economic savings compared to the baseline conditions (do-nothing alternative). Delay cost was computed by multiplying the delay (vehicle-hours) times one-half of the average hourly wage in Baton Rouge (0.5 x $\$ 21.38 /$ hour $=\$ 10.69 /$ hour $)$. For every proposed solution, the average of the 10 simulation runs was computed for every MOE for further analysis and evaluation.

\section{Findings, conclusions, recommendations}

Results of the VISSIM simulations of the proposed solutions are summarized in the project's final report [7]. Table 3 presents comparison of the effectiveness of the different strategies and treatments included in this study. Based on the results of the simulation scenarios, the following conclusions have been reached:

- A combination of supply-oriented and demand oriented strategies/treatments must be implemented to relieve congestion on I-10 in Baton Rouge.

- Rehabilitating the old Mississippi River Bridge and Reconstructing the US-190/US-61 Corridor will shift some of the I-10 eastbound traffic to the old bridge. This will improve traffic flow on the I-10 Mississippi River Bridge and produce notable reduction in the vehicle-hours of delay and annual user costs during the A.M. and P.M. peak periods.

- Implementation of local traffic demand management strategies (telecommuting, improved transit service, promoting integrated land-use and transportation planning, etc.) can produce immediate reduction in traffic delays on I-10 during the A.M. and P.M. peak periods.

- Ramp Metering/Local Demand Optimization at the Alexander Avenue on-ramp west of the I-10 Mississippi River Bridge during the P.M. peak period can result in notable reduction in delays and user costs.

- $\quad$ Reducing Percent Trucks on I-10 eastbound during the A.M. peak period at the Alexander Avenue onramp can result in notable improvement in traffic operations. This solution may be difficult to implement and requires close cooperation of local industries and businesses.
The results of this study should be considered with an important caveat in mind: the data available to the researchers for calibrating and validating the simulation model were very limited. As such, additional data on key traffic parameters (e.g., flow rate, average speed, and traffic density) as well as demand-related data (e.g., traveler preferences and perceptions, route choice, mode choice, etc.) are required to confirm the numerical values of the MOE's and metrics included in the report.

\section{References}

1. Urban Systems, Inc. Traffic Study for I-10 Stage-0 Feasibility Study, 2016. Available from: https://filestogeaux.lsu.edu/public/download.php?FI $\underline{\mathrm{LE}=\text { jcodjo1/24163ezgxlf }}$

2. LADOTD. I-10 Baton Rouge Major Investment Study, 2000.

3. LADOTD. I-10 Corridor Improvements Stage-0 Feasibility Study, 2016. Available from: https://i10br.com/wpcontent/uploads/2016/08/Feasibility-Study I-10Corridor-Report-Only July-2016.pdf

4. Ascension, East Baton Rouge, Iberville, Livingston, and West Baton Rouge Parishes, Louisiana. Baton Rouge Loop: Tier 1 Final Environmental Impact Statement, 2015. Available from: http://brloop.com/pdf/01_Baton\%20Rouge\%20Loop \%20Tier\%201\%20FEIS\%20Volume\%201.pdf

5. Will Sentell. I-10 Widening Plan in Baton Rouge includes Major Changes to these exists; Here's What Comes Next. The Advocate, February 17, 2018. Available from:

http://www.theadvocate.com/baton_rouge/news/poli tics/article 5d266efc-0126-11e8-88a3-

7b74351f722a.html

6. AECOM, the Baton Rouge Renewal and Mobility Plan (BUMP). December 2014. Available from: http://wwwsp.dotd.la.gov/Inside LaDOTD/Division s/Administration/LTA/Misc\%20Documents/AECO M\%20Unsoliticed\%20Proposal\%20BUMP.pdf

7. Ahmed, S.A., and Osman, O.A. (2018). Mitigating Traffic Congestion on I-10 in Baton Rouge, LA: Supply- and Demand-Oriented Strategies and Treatments. Final Report, Project No. 17ITSLSU09, Tran-SET UTC, 2018. 
Table 2. Summary of strategies/ treatments.

\begin{tabular}{|c|c|c|c|}
\hline Category & Strategy/Treatment & Description or Application & Modes Affected \\
\hline \multirow{2}{*}{$\begin{array}{l}\text { Supply-Oriented } \\
\text { Strategies/Treatments }\end{array}$} & $\begin{array}{c}\text { Minimize turbulence and queuing } \\
\text { caused by excessive lane changes } \\
\text { upstream of problem exit ramps }\end{array}$ & $\begin{array}{l}\text { Traffic diverging from I- } 10 \text { at the } \\
\text { Washington Street exit is directed to the } \\
\text { Dalrymple exit during the A.M. peak } \\
\text { period. }\end{array}$ & $\begin{array}{l}\text { Passenger vehicles } \\
\text { and trucks }\end{array}$ \\
\hline & $\begin{array}{l}\text { Infrastructure improvements, } \\
\text { geometric design treatments, } \\
\text { signal timing (Old US-190 } \\
\text { Mississippi River Bridge and the } \\
\text { US-190/US-61 Corridor) }\end{array}$ & $\begin{array}{l}\text { - Rehabilitation of the old Mississippi } \\
\text { River Bridge on US-190 } \\
\text { - Reconstruction of the US-190/US-61 } \\
\text { Corridor } \\
\text { - Signal timing improvements }\end{array}$ & $\begin{array}{l}\text { Passenger vehicles, } \\
\text { trucks and transit }\end{array}$ \\
\hline \multirow{3}{*}{$\begin{array}{l}\text { Demand-Oriented } \\
\text { Strategies/Treatments }\end{array}$} & Ramp Metering & $\begin{array}{l}\text { Demand optimization to keep demand } \\
\text { and capacity in balance. Ramp metering } \\
\text { for eastbound traffic coming from the } \\
\text { Alexander Avenue on-ramp west of the } \\
\text { I-10 bridge during the P.M. peak period }\end{array}$ & $\begin{array}{l}\text { Passenger vehicles } \\
\text { and trucks }\end{array}$ \\
\hline & $\begin{array}{l}\text { Local Traffic Demand } \\
\text { Management }\end{array}$ & $\begin{array}{l}\text { - Employee telecommuting options } \\
\text { - Expanding and improving transit } \\
\text { services to make public transportation } \\
\text { easier and more attractive to use } \\
\text { - Bike lanes } \\
\text { - Flextime or staggered work hours. } \\
\text { - Adopting congestion pricing } \\
\text { - Promoting integrated transportation } \\
\text { and land-use planning } \\
\text { - Preferential parking for carpools and } \\
\text { vanpools, employee parking cash-out }\end{array}$ & $\begin{array}{l}\text { Passenger vehicles } \\
\text { and transit }\end{array}$ \\
\hline & Reduction in Truck Traffic & $\begin{array}{l}\text { Reduction in truck volume at the } \\
\text { Alexander Avenue on-ramp during the } \\
\text { A.M. peak period }\end{array}$ & Trucks \\
\hline
\end{tabular}

Table 3. Comparison of strategies/treatments.

\begin{tabular}{|c|c|c|c|c|}
\hline Strategy/Treatment & \multicolumn{2}{|c|}{ Impact on Reducing Congestion } & Cost & Barriers to Implementation \\
\hline $\begin{array}{l}\text { Minimize turbulence and queuing } \\
\text { caused by excessive lane changes } \\
\text { upstream of problem exit ramps }\end{array}$ & Low & $\begin{array}{l}\text { - Improve traffic flow } \\
\text { and safety }\end{array}$ & Low & $\begin{array}{l}\text { - Public Acceptance } \\
\text { - Difficult to implement }\end{array}$ \\
\hline $\begin{array}{l}\text { Infrastructure improvements, geometric } \\
\text { design treatments, signal timing (Old } \\
\text { US-190 Mississippi River Bridge and } \\
\text { the US-190/US-61 Corridor) }\end{array}$ & High & $\begin{array}{l}\text { - Improved mobility } \\
\text { and traffic flow } \\
\text { - Improved capacity } \\
\text { - Reduced congestion } \\
\text { - Reduced delays to } \\
\text { travelers and shippers }\end{array}$ & Medium & $\begin{array}{l}\text { - Limited elected leader support } \\
\text { - Lack of funding }\end{array}$ \\
\hline Ramp Metering & Medium & $\begin{array}{l}\text { - Improve traffic flow } \\
\text { and safety } \\
\text { - Reduced congestion } \\
\text { - }\end{array}$ & Low & - Public Acceptance \\
\hline Local Traffic Demand Management & High & $\begin{array}{l}\text { - Improved mobility } \\
\text { and traffic flow } \\
\text { - Reduced congestion } \\
\text { - Reduced delays to } \\
\text { travelers and shippers }\end{array}$ & Low & $\begin{array}{l}\text { - Public Acceptance } \\
\text { - Employer/agency buy-in } \\
\text { - }\end{array}$ \\
\hline Reduction in Truck Traffic & Medium & $\begin{array}{l}\text { - Reduced congestion } \\
\text { - Reduced delays to } \\
\text { travelers and shippers }\end{array}$ & Low & $\begin{array}{l}\text { - Cooperation of local Industries an } \\
\text { businesses } \\
\text { - Difficult to implement }\end{array}$ \\
\hline
\end{tabular}

